\title{
Climate Change Impacts on Personal Insurance
}

\author{
Gilles Benoist \\ CNP Assurances SA, Place Raoul Dautry 4, Paris 75716, France. \\ E-mail: gilles.benoist@cnp.fr
}

Global warming due to human activities triggers different consequences according to the impacted areas. In the north, it causes material damage that insurance, financial, and technical means can help to cope with. In the south, it brings about heavy human losses, accentuated by demography, lack of infrastructure, and low insurance coverage. For the moment, climate change has had little impact on personal insurance results. However, to face the worldwide multiplication of disasters and epidemics predicted by the experts, personal insurers could play an increasing role. They could establish more accurate statistics to evaluate and price the risks. They could also promote risk prevention among their policyholders. As for emerging countries, developing insurance coverage would be the best way to face the consequences of climate change.

The Geneva Papers (2007) 32, 16-21. doi:10.1057/palgrave.gpp.2510122

Keywords: global warming; disasters; human losses; insurance coverage; risk evaluation; risk prevention

\section{A new challenge}

The development of scientific knowledge and technologies during the 20th century has permitted an unprecedented improvement in life conditions.

On health matters, the benefits are obvious. In France, for example, life expectancy has increased from 45 to 80 years in the last century. On the other hand, this rapid increase in human population and our modern way of life - huge energy consumption, intensity of land use, international trade and travel, and other human activities - are bringing about a global climate change.

Global warming is proven. The third report of the United Nation's Intergovernmental Panel on Climate Change (IPCC) stated that "during the twentieth century, world average surface temperature increased by approximately $0.6^{\circ} \mathrm{C}$, approximately two-thirds of that warming has occurred since 1975. There is new and stronger evidence that most of the warming over the last 50 years is attributable to human activities".

Global warming affects the whole planet but in varying ways on the different continents. Storms, floods, heat waves, drought, hurricanes, fires, landslides follow one another all over the world. It causes death and injuries immediately. It also affects health in the middle and long term.

\section{Material damage in the North, heavy human losses in the South}

The human consequences depend largely on the impacted area. The figures speak for themselves. Lothar, the storm that swept across Europe in December 1999, caused 111 
deaths and the cost for insurers was US\$6.8 billion. From 1995 to 2004, Europe had to face 30 major floods, which caused 1,000 deaths and affected 2.5 million people. Recently, Katrina caused 1,326 deaths and the insurance cost was US\$45 billion, mainly for material damage.

In France, the August 2003 heat wave showed our health system incapable of coping with a relatively common problem in southern European countries. We estimate that 15,000 deaths were due to this heat wave. It was a high number in a short period of time, but in fact only had a small impact on the average number of annual deaths (552,000 deaths in 2003 and 535,000 in 2002). Nevertheless, from 2002 to 2005, life expectancy progressed more than expected, from 75.8 to 76.8 years for men and from 83 to 83.8 years for women. The heat wave has had at least one positive consequence in France: people have become aware of the fragility of the aged and this, in turn, has led to a sustainable change of behavior towards the elderly, with positive effects on mortality.

On the contrary, in the south, human losses have been heavy. Bangladesh has paid the highest price: the storm and flooding in November 1970 caused 300,000 deaths, the deadliest disaster yet. The earthquake in the Chinese city of Tan-shan took 250,000 lives in 1976. And the tropical cyclone Gorky in 1991 was fatal to 138,000 people.

In December 2004, the tsunami, triggered by the most violent earthquake in 40 years, killed more than 220,000 persons, ranking third in the list of natural disasters since 1970. The victims lived mainly in Indonesia (167,500), Sri Lanka (35,000), India $(16,000)$, and Thailand $(8,000)$. Forty other countries had 2,000 citizens among the dead. Germany and Sweden were the worst affected outside the region, each with more than 500 people killed. The amount of damage was estimated at US\$13 billion, but the global cost for insurers was only US\$2 billion as the tsunami hit mainly local populations who had no insurance coverage. Concerning the 2005 natural disasters, 87 per cent of the material damage was in North America, but 92 per cent of the human losses occurred in Asia.

\section{Different consequences according to the country}

Consequences depend also on the development level of the impacted areas. Advanced societies have the financial and technical possibilities to cope with the effects of weather disasters. After the heat wave of August 2003, the French government assessed the final toll of the disaster and designed a "heat plan", consisting of three types of actions:

(1) An alarm system based on a partnership between Météo France, which publishes a daily map called "heat vigilance", and the health authorities. The Institut de veille sanitaire (InSV) gathers the data coming from Météo France, the emergency services in hospitals and the firemen. The InSV is in charge of alerting the Health Department in case of a heat wave. There are three alarm levels according to temperature: the "seasonal watch", the "warning and action", and the "maximal mobilization".

(2) Actions were carried out in retirement homes and hospitals. Retirement homes were obliged by law to set up air-conditioned rooms. These facilities are subsidized 
up to 40 per cent of the total amount by the Government, with the result that today nearly 100 per cent of retirement homes are equipped, against 13 per cent in 2003. To avoid overbooking the hospital emergency wards, a list of all general practitioners present during the summer is available by calling a phone number. Lastly, funds were granted to hospitals to appoint seasonal workers or to pay overtime hours.

(3) As loneliness is an additional risk factor, the "heat plan" suggests that the population at risk register on a list. When the alarm is activated, the local authorities, with the help of associations, visit the frailest old persons and deliver bottles of water.

The "heat plan" proved its efficiency in July 2006. The Institut national de prévention et d'éducation pour la santé launched radio campaigns to encourage citizens to be aware of their frailer neighbors. Prevention messages were largely relayed by the media.

In spite of the exceptionally long heat wave, there were no more deaths due to it than in each of the past 3 years: 112 deaths, including 66 old people, compared to 15,000 deaths in 2003.

In the emerging countries, demography and lack of infrastructures increase the number of victims. Most of the developing countries are located in areas where global climate change produces its worst effects. Extreme weather conditions in tropical, subtropical, and desert climates are accentuated and endemic diseases in tropic or subtropical areas spread rapidly.

Furthermore, the countries have not yet enough resources to face natural disasters. In the case of the tsunami of December 2004, populations had little chance to survive because no warnings were given in time. However, the first waves hit Sumatra within 30 minutes, Bangladesh and Thailand 30 to 60 minutes later, which would have been sufficient to escape for at least part of the victims. But, except in Japan and Hawaii, local populations do not benefit from adequate alarm systems and preventive education. Those systems are expensive and they are not considered as a priority when the living standards are low.

Emerging economies are threatened. Means used to face disasters are no longer available for economic and social development, and populations become more and more vulnerable.

\section{A feeble impact on personal insurance results for the moment}

It is very difficult to know precisely the real impact of climate change on personal insurance.

In the north, for the moment, the number of deaths is limited and has no effect on the global mortality rate. Besides, it is often difficult to weigh up the part due to climate disasters in the morbidity increase since the consequences of climate change could have been compensated by other factors. In the developed world, insurance can help deal with the effects of natural disasters.

In the south, the insurance cost of natural disasters is low due to the very low insurance coverage, especially in personal insurance. Life insurance in the emerging 
countries represented only 12 per cent of the total premiums in 2005, while the inhabitants accounted for about 85 per cent of the world population.

\section{Numerous questions for the future}

This situation raises numerous questions for the future. Global warming will probably not slow down in the near future. On the contrary, pollution will worsen as emerging countries adopt our way of life and increase their energy consumption.

We can be sure that consequences on health will mainly be negative. Heat waves may increase the mortality rate even in the north. For instance, the annual excess summer-time mortality attributable to climate change by 2050 is estimated to increase several fold.

Experts predict the following:

- A multiplication of some pathologies due to heat and humidity, either directly, such as gastro-enteritis, diarrheas, salmonellas, or via the multiplication of transmission vectors (mosquitoes) such as lyme disease, malaria, etc.

- A geographical expansion of tropical infections such as dengue fever, and these tropical diseases could spread all over the world due to tourism.

- A rise in heart and respiratory diseases: pollution that is worsened by global warming is responsible for more allergies and asthma.

- An increase in skin cancers due to greater exposure to the sun.

- Disasters and epidemics will lead to an increase in psychological diseases. The death of loved ones or the displacement of populations may provoke mental diseases.

- Last but not least, displaced populations and famines could also bring about conflicts.

Concerning the consequences on personal insurance, experts reckon that a bird flu pandemic, for example, hitting mainly the working population, such as the Spanish flu in 1918, could have heavy consequences. It could impact the technical results of health and death contracts, though this could be compensated in some countries by benefits in annuity products. And it would probably impact the financial results, due to a downturn in the global commercial exchanges and economic activity, followed by a crisis of the stock markets worldwide.

However, these possible effects could be limited by preventive behavior in which personal insurers could take part.

\section{The increasing role of personal insurance}

Personal insurers, whose responsibility is to protect policyholders and their families from the risks of day-to-day life and who are involved in key issues facing the society, could play an increasing role in facing the consequences of the global climate change.

Insurers can expect to play three main roles:

(1) They will have to evaluate risks more precisely to be able to price and cover them. Until now, natural disasters linked to climate change have had little impact on personal insurance results. However, insurance development in the south where the 
consequences of climate change are higher will lead insurers to evaluate risks more accurately to accumulate enough capital to face the claims.

Pricing is based on accurate statistics (mortality and morbidity rates linked to disasters, frequency of events...), which are difficult to establish for largely unpredictable weather disasters. But large natural disasters, such as the South Asia tsunami, can help to improve understanding of how a tsunami propagates and to better assess the risk. Actuaries and organisations such as the World Health Organisation, which is working on the impact of climate change on health in the long term, must also develop new tools to evaluate the effects of the climate change on human morbidity and mortality.

\section{Taking up the challenge of prevention}

(2) Insurers need to promote risk prevention and encourage their clients to adopt the appropriate behavior.

Personal insurers can encourage socially responsible behavior in the companies in which they invest. CNP Assurances incorporates sustainable development criteria in its analyses, using internally developed information such as non-financial data, social responsibility rating agencies, questionnaires, interviews, and so on. A certain proportion of its own portfolio is invested in socially responsible investment funds. And it also offers ethical investments to its group insurance clients. As the largest private owner of forests in France, CNP Assurances forest management is based on sustainable management guidelines that led it to obtain the Program for the endorsement of Forest certification (PEFC). An insurance company can help to limit global climate change by adopting environmentally sound practices, such as energysaving measures and paper and waste recycling.

Personal insurers can make their policyholders aware of the dangers of climate change and develop risk prevention. Until now, in Europe, particularly in France, development of personal insurance has aimed at maintaining the same standards of living and health to people living longer. However, the fear of risk reinforces the need for insurance. And new risks give rise to new needs in insurance all over the world. People are looking not only for financial cover in case of disease or death, but also for more and more services.

To meet the needs of their clients, insurers are developing innovative services linked to insurance contracts. Studies prove that people attach great value to information. In France, more and more insurers have set up 24/7 call centers in charge of delivering information about risks and diseases and the ways to avoid them. Regarding the diseases linked to global climate change, insurers are providing practical health information on required vaccination in the different regions, dangers of great sun exposure, precautions to take in case of heat waves, and so on.

Personal insurers are also developing assistance services, such as psychological help, making contact between clients and providers, portals offering information and solutions adapted to the needs of their clients. 


\title{
Helping to develop insurance in the emerging countries
}

(3) Insurers would have to help take up the challenges of development. At the world level, solutions are mainly the matter of intergovernmental decisions, within the scope of the Kyoto agreements. At the national and local levels, insurers must participate in conferences and roundtables to share information and help governments to implement innovative solutions. Concerning natural disasters such as the South Asia tsunami for example, insurers can help understand the phenomenon and set up appropriate preventive alarm systems to avoid high human and material losses.

Because of globalisation and links between economics and health, insurance must be developed in the emerging countries. The increase in the standards of living tends to raise the need for insurance worldwide, non-life as well as personal insurance.

But insurers have to adapt their methods and products to emerging countries, first by defining what can be insured and secondly by finding how to cover the financial risk. Micro-insurance, linked to micro-credit and consisting in offering essential lowcost guarantees adapted to the specific needs of emerging countries, could help to increase the standard of living and to cope with some of the climate change consequences worldwide.

\begin{abstract}
About the Author
Gilles Benoist, born on 12th December, 1946, is Chairman of the Executive Board, CNP Assurances (1998). He is a Graduate of the Institut d'Etudes Politiques - Paris (Political Science Institute) and a Graduate of the Ecole Nationale d'Administration "Simone Weil" year (French Senior Civil-Service Training Institute). He was a public auditor at the Cour des Comptes, French Audit Office from 1983 to 1987; General Secretary of Credit Local de France, Member of the Management Board, and Advisor to the Director of the Local Development Department of Caisse des Dépôts et Consignations from 1987 to 1991; Director of Federal Support Services of Caisse des Dépôts et Consignations from 1991 to 1993; and Corporate Secretary and Human Resources Director from 1993 to 1998. In December 1996, he became Conseiller Maître à la Cour des Comptes, French General Accounting Office.
\end{abstract}

